\title{
Peripheral Slits Microstrip Antenna Using Log Periodic Technique for Digital Television Broadcasting
}

\author{
Indra Surjati* ${ }^{1}$, Yuli Kurnia Ningsih ${ }^{2}$, Syah Alam ${ }^{3}$ \\ ${ }^{1,2}$ Graduate Programme of Electrical Engineering, Faculty of Industrial Technology Trisakti University, JIn. \\ Kyai Tapa No.1 Grogol, Jakarta 11440 \\ ${ }^{3}$ Electrical Engineering Departement, Faculty of Engineering $17^{\text {th }}$ August University \\ Corresponding author, e-mail: indra@trisakti.ac.id², syah.alam@uta45jakarta.ac.id ${ }^{3}$
}

\begin{abstract}
This paper proposed a new design of log periodic microstrip antenna using peripheral slits for dgital video broadcasting applications in DKI Jakarta. Applying peripheral slits can be reduced the dimension of antenna up to $62.6 \%$ with its dimension $400 \mathrm{~mm} \times 150 \mathrm{~mm}$ using 4 patches in different frequencies. The patches are one another connected using log periodic technique. The measurement results showed that the antenna was operating at frequency ranges of $450 \mathrm{MHz}$ to800 $\mathrm{MHz}$ with impedance bandwidth of $350 \mathrm{MHz}, V S W R \leq 2$ and return loss $\leq-10 \mathrm{~dB}$. The proposed antenna could receive 11 DVB stations with high definition quality pictureand only channel number 24 , such as RCTI, Global TV and MNC TV can not reveive signals as expected.
\end{abstract}

Keywords: digital video broadcasting, peripheral slits, log periodic, microstrip antenna

Copyright @ 2017 Universitas Ahmad Dahlan. All rights reserved.

\section{Introduction}

Digital television broadcasting is a technology that can not be avoided by any country in the world. The development of digital television broadcasting technology becomes a global demand which nearly each country has and in the process towards the transition from analogue to digital broadcasting systems. The advantages of digital television broadcasting such as high definition picture quality, sound system are of sharper and better efficient allocation of radio frequencies [1].

Digital television broadcasting standard has been also developed from Digital Video Broadcasting-Terrestrial (DVB-T) to Digital Video Broadcasting - Second Generation Terrestrial (DVB-T2). The Indonesian Government has adopted the regulation on standard fixed and not paid Digital Terrestrial Television Broadcasting (free-to-air); known as DVB-T2 digital terrestrial television broadcasting free-to-air standar in Indonesiaas manifestated with the Minister of Communications and Information Technology Regulation No. 05/PER/M.KOMINFO/2/2012 [2]. Beside this regulation, the digital television system in Indonesia also follows the Regulation of Minister of Communication and Information Technology Number 23/PER/M.KOMINFO/11/2011 on the Master Plan of Radio Frequencies for Television Broadcasting in the Digital Terrestrial Radio Frequency Bands between $478 \mathrm{MHz}-694 \mathrm{MHz}$ [3].

Several studies related to the producing of digital television receiver antennas with certain expected characteristics were the use of slot technique that produced a dimension of (204.8 x 160.6) $\mathrm{mm}$ with omnidirectional radiation pattern and VSWR $\leq 2$ [4], research already done by [5] using 5 pieces of element patch log periodic that produced dimension of (169.4 $\mathrm{x}$ 113.8) $\mathrm{mm}$, and producing a $2 \times 2$ array antenna with dimension of $(515 \times 300) \mathrm{mm}$ [6]. Another research done by [7] proposed a linear array antenna.

In addition to the above as well findings there were some researches conducted using log periodic technique, such as have been done by [8-9] using log periodic dipole array antenna fed by coaxial probe. Another research done by [10] using rectangular patch antenna fed by microstrip line, while [11] was also done using rectangular patch antenna fed by coplanar waveguide. The research done by [12] used elliptical patch antenna fed by microstrip line.

Peripheral slits were able to produce a compact antenna with smaller dimension. This technique could reduce microstrip patch antenna up to $33 \%$ of its original size. Therefore 
peripheral slits technique is one method to optimize the microstrip antenna dimension [13]. Peripheral slits is a method of miniaturization techniques microstrip antenna by using some slits on patch antenna.

Based on previous studies results it can be inferred that the peripheral slits method can reduce antenna size. Therefore this paper proposed a new design of peripheral slits microstrip antenna using log periodic technique fed by microstrip line.

\section{Antenna Design}

The design of the proposed antenna is made based on one layer substrate with relative permitivity $(\boldsymbol{\varepsilon} r)$ of 4.3 , substrate thicknes $(\boldsymbol{h})$ of $1.6 \mathrm{~mm}$ and loss tangent $(\boldsymbol{t a n} \boldsymbol{\delta})$ of 0.0265 . The dimensions of the rectangular patch antenna are given by the equations as follows.

$$
\begin{aligned}
& W=\frac{\mathrm{c}}{2 f r \sqrt{\frac{(\varepsilon r+1)}{2}}} \\
& \varepsilon e=\frac{(\varepsilon r+1)}{2}+\frac{(\varepsilon r-1)}{2}\left(\frac{1}{\sqrt{1+12 \mathrm{~h} / \mathrm{w}}}\right) \\
& \text { Leff }=\frac{\mathrm{c}}{2 f r \sqrt{\varepsilon e}} \\
& \tau=\frac{f 1}{f 2}
\end{aligned}
$$

By embedding a stub at the microstrip line, the matching condition can be well achieved and the value of return loss and VSWR can be improved by adjusting the length and width of the stub. Having several iterations related those parameters, afterward peripheral slits was embedded to reduce the dimension of the patch antenna.

The antenna can be applied at various frequencies as presented by Table 1 for Digital Television Broadcasting application in DKI Jakarta Region.

Table 1. DVB Frequencies for DKI Jakarta Region

\begin{tabular}{cccc}
\hline No & Patch & Channel & Frequency \\
\hline 1 & RCTI, Global TV, MNC TV & 24 & $498 \mathrm{MHz}$ \\
2 & Metro TV & 32 & $562 \mathrm{MHz}$ \\
3 & TV One, ANTV and Sport One & 34 & $578 \mathrm{MHz}$ \\
4 & BeritaSatu TV (BSTV) & 36 & $594 \mathrm{MHz}$ \\
5 & Transcorp (Trans TV, Trans 7) and & 40 & $626 \mathrm{MHz}$ \\
6 & Kompas TV & 44 & $658 \mathrm{MHz}$ \\
7 & SCTV, Indosiar, and O Channel & 48 & $690 \mathrm{MHz}$ \\
\hline
\end{tabular}

All of those frequencies in Table 1 are classified into four groups of patches as shown in Table 2. These all four patches are combined using log periodic technique which is shown in Figure 1. The patches size and dimension, as shown by Figure 1, are differ one to another which are given by Table 3 . The length of microstrip line of log periodic antenna is $Z_{L}$ of $332.6 \mathrm{~mm}$.

Table 2. Frequency of Each Patch Antenna

\begin{tabular}{ccc}
\hline No & Patch & Frequency \\
\hline 1 & Patch 1 & $580 \mathrm{MHz}$ \\
2 & Patch 2 & $630 \mathrm{MHz}$ \\
3 & Patch 3 & $670 \mathrm{MHz}$ \\
4 & Patch 4 & $720 \mathrm{MHz}$ \\
\hline
\end{tabular}


Table 3. Dimension and Size of Log Periodic Peripheral Slit Microstrip Antenna

\begin{tabular}{|c|c|c|c|c|}
\hline atch 1 & $\mathrm{~W} 1=77.4 \mathrm{~mm}$ & $\mathrm{~L} 1=89.5 \mathrm{~mm}$ & $\mathrm{Y} 1=27.8 \mathrm{~mm}$ & $\mathrm{Ls} 1=24 \mathrm{~mm}$ \\
\hline $\operatorname{ch} 2$ & $\mathrm{~W} 2=77 \mathrm{~mm}$ & $\mathrm{~L} 2=80 \mathrm{~mm}$ & $\mathrm{Y} 2=28 \mathrm{~mm}$ & $=24 \mathrm{~mm}$ \\
\hline atcr & $\mathrm{W} 3=65 \mathrm{~mm}$ & $\mathrm{~L} 3=73 \mathrm{~mm}$ & 23 mm & $\mathrm{Ls} 3=14 \mathrm{~mm}$ \\
\hline Patch 4 & $\mathrm{~W} 4=58 \mathrm{~mm}$ & $\mathrm{~L} 4=65 \mathrm{~mm}$ & $Y 4=23 \mathrm{~mm}$ & $\mathrm{Ls} 4=14 \mathrm{~mm}$ \\
\hline
\end{tabular}

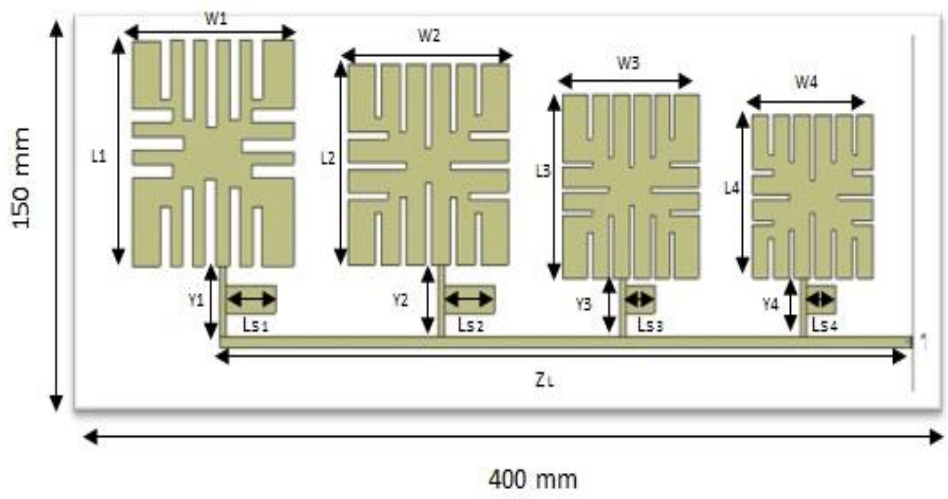

Figure 1. Peripheral Slits Microstrip Antenna Using Log Periodic Technique

\section{Results and Analysis}

Return loss and VSWR value can be obtanined after having several iterations by adjusting the width and length of the patch antenna and also the dimension of the slits. To produce the best value of return loss and VSWR can be achieved by controlling the length of the microstrip line and the stub length, and the outcome of return loss and VSWR can be seen in Figure 2.

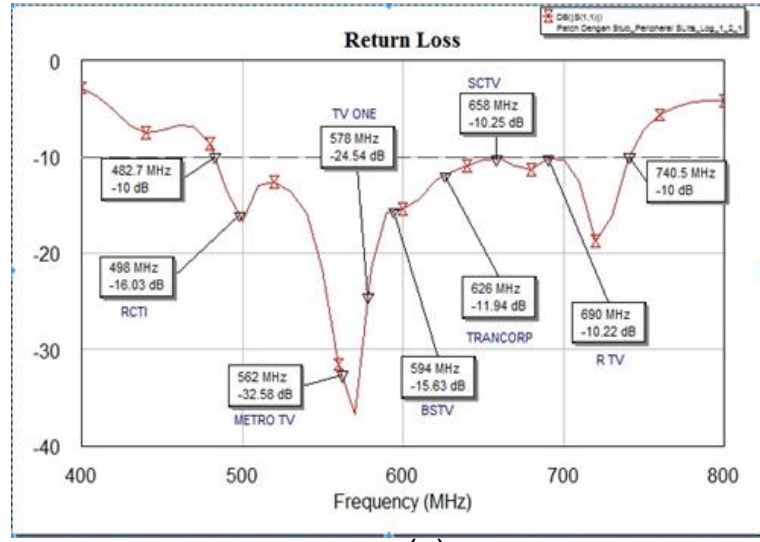

(a)

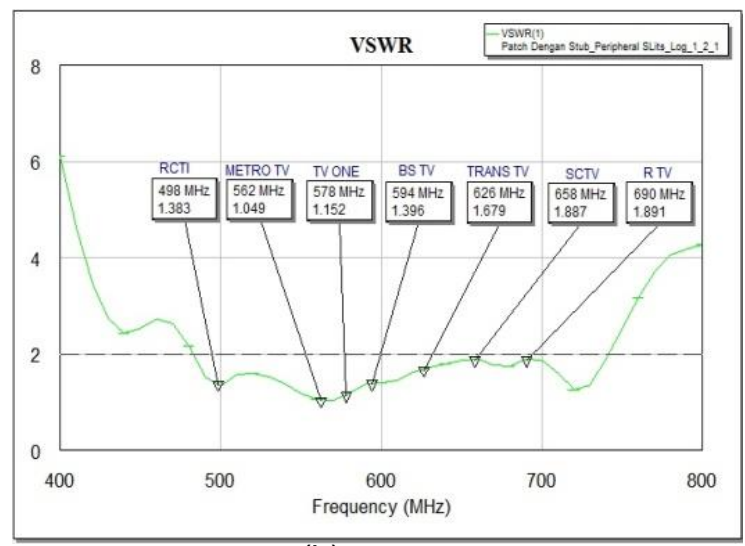

(b)

Figure 2. Results from (a) Return Loss Value and (b) VSWR Value

The overall iteration are summarized in Table 3 for the parameters of the proposed antenna and in Table 4 for the return loss value. Its can be seen the return loss results of $\leq-10$ $\mathrm{dB}$ in the range of $482.7 \mathrm{MHz}$ to $740.5 \mathrm{MHz}$ can be achieved at the third iteration by varying the parameters of the width of the second patch (W2), the length of the first patch (L1) and the length of the second patch (L2). 
Table 3. Iterations of the parameters antenna

\begin{tabular}{ccccccccc}
\hline \multirow{2}{*}{ Iterations } & \multicolumn{7}{c}{ Parameters $(\mathrm{mm})$} \\
& W1 & W2 & W3 & W4 & L1 & L2 & L3 & L4 \\
\hline 1 & 77.4 & 70 & 65 & 58 & 83.5 & 80 & 73 & 65 \\
2 & 77.4 & 73 & 65 & 58 & 83.5 & 73 & 73 & 65 \\
3 & $\mathbf{7 7 . 4}$ & $\mathbf{7 7}$ & $\mathbf{6 5}$ & $\mathbf{5 8}$ & $\mathbf{8 9 . 5}$ & $\mathbf{8 0}$ & $\mathbf{7 3}$ & $\mathbf{6 5}$ \\
\hline
\end{tabular}

Table 4. Return Loss Results

\begin{tabular}{cccccccc}
\hline \multirow{2}{*}{ Iteration } & \multicolumn{7}{c}{ Return Loss $(\mathrm{dB})$} \\
& C.24 & C.32 & C.34 & C.36 & C.40 & C.44 & C.48 \\
\hline 1 & -11.6 & -25.9 & -17.8 & -28.5 & -11.7 & -9.3 & -13.1 \\
2 & -6.3 & -15.7 & -14.6 & -14.3 & -21.7 & -12.7 & -12.7 \\
3 & $\mathbf{- 1 6 . 0}$ & $\mathbf{- 3 2 . 6}$ & $\mathbf{- 2 4 . 6}$ & $\mathbf{- 1 5 . 6}$ & $\mathbf{- 1 1 . 9}$ & $\mathbf{- 1 0 . 3}$ & $\mathbf{- 1 0 . 2}$ \\
\hline
\end{tabular}

The fabrication of the proposed microstrip antenna design was done after the simulation of the third iteration process. FR4 Epoxy substrate and SMA connector which have $50 \mathrm{Ohm}$ impedance value are used in this fabrication and the fabrication result can be seen in Figure 5 .

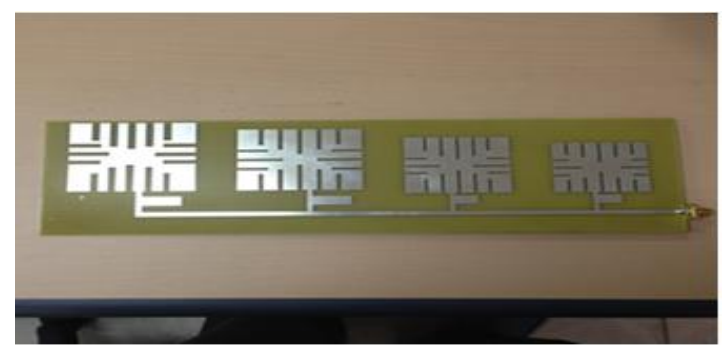

Figure 5. Fabrication of microstrip antenna design

After the fabrication, the measurements of return loss and VSWR have been done in the laboratory as seen in Figure 6 and Figure 7. From Figure 6 it can be sen that the proposed antenna can work at the range frequency between $498 \mathrm{MHz}$ to $690 \mathrm{MHz}$ for Digital Television Broadcast application in DKI Jakarta Region.The impedance bandwidth of the measurement result is $350 \mathrm{MHz}(450 \mathrm{MHz}-800 \mathrm{MHz})$ compared to $257.8 \mathrm{MHz}(482.7 \mathrm{MHz} 740.5 \mathrm{MHz})$ from the simulation process. It can be seen that the impedance bandwidth from the proposed antenna is increased up to $35.76 \%$.

From Figure $7, V S W R \leq 2$ from the proposed antenna can be achieved in the frequency range $470 \mathrm{MHz}$ to $740 \mathrm{MHz}$.

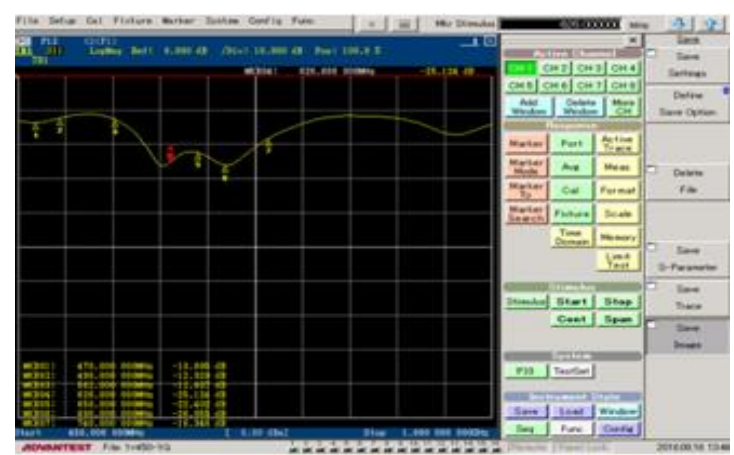

Figure 6. Measurement of Return Loss 


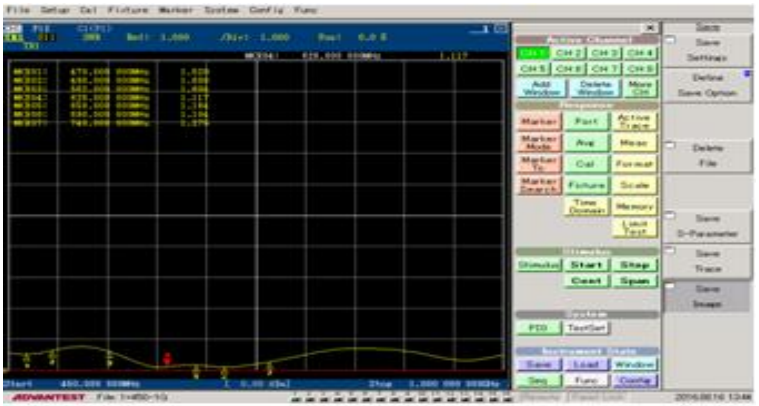

Figure 7. Measurement of VSWR

The results of return loss and VSWR of the simulation and measurement are tabulated in Table 5 and the graphic of the comparison are seen in Figure 8 and Figure 9 below. From Table 5 it can be seen that all of the return loss value is $\leq-10 \mathrm{~dB}$ and also the VSWR value is $\leq 2$. With this results indicated that all of the channel of DVB stations can receive the signal.

Table 5. Comparison Simulation and Measurement of Return Loss and VSWR

\begin{tabular}{cccccc}
\hline Channel & $\begin{array}{c}\text { Working } \\
\text { Frequency }\end{array}$ & $\begin{array}{c}\text { Return Loss } \\
\text { Simulation } \\
\text { Results (dB) }\end{array}$ & $\begin{array}{c}\text { Return Loss } \\
\text { Measurement } \\
\text { Results (dB) }\end{array}$ & $\begin{array}{c}\text { VSWR } \\
\text { Simulation } \\
\text { Results }\end{array}$ & $\begin{array}{c}\text { VSWR } \\
\text { Measurement } \\
\text { Results }\end{array}$ \\
\hline 24 & $498 \mathrm{MHz}$ & -16.0 & -12.3 & 1.38 & 1.64 \\
32 & $562 \mathrm{MHz}$ & -32.6 & -12.7 & 1.05 & 1.59 \\
34 & $578 \mathrm{MHz}$ & -24.6 & -15.0 & 1.15 & 1.43 \\
36 & $594 \mathrm{MHz}$ & -15.6 & -18.9 & 1.40 & 1.24 \\
40 & $626 \mathrm{MHz}$ & -11.9 & -25.1 & 1.68 & 1.12 \\
44 & $658 \mathrm{MHz}$ & -10.3 & -22.4 & 1.89 & 1.14 \\
48 & $690 \mathrm{MHz}$ & -10.2 & -26.0 & & 1.1 \\
\hline
\end{tabular}

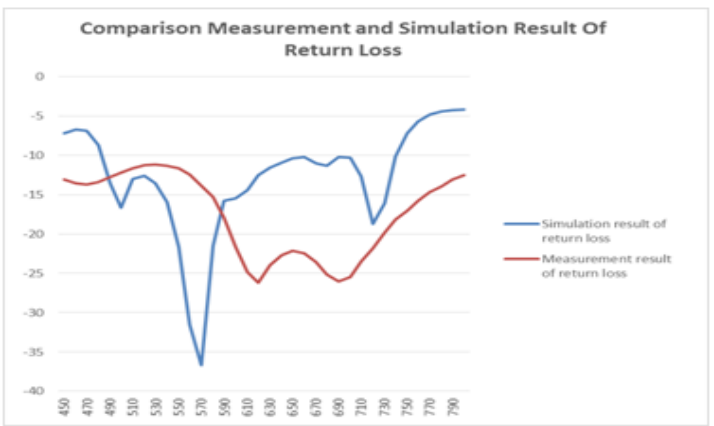

Figure 8. Comparison Measurement and Simulation Results of Return Loss

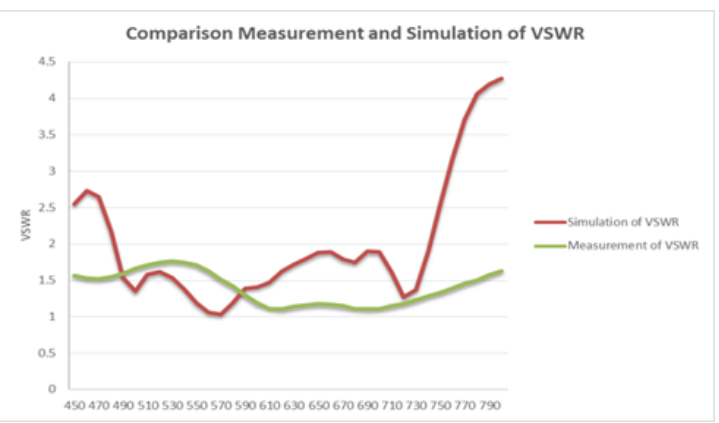

Figure 9. Comparison Measurement and Simulation Results of VSWR 
Figure 10 shown the radiation pattern from the proposed antenna design with Half Power Beamwidth (HPBW) of $120^{\circ}$ and its indicated that the radiation pattern is broadside.

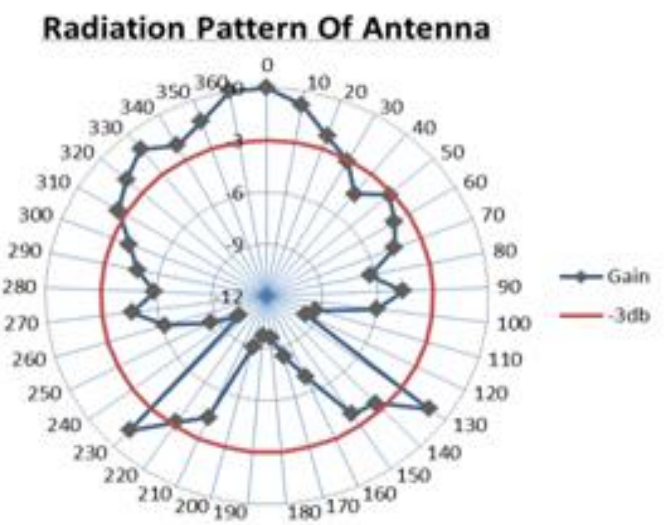

Figure 10. Radiation pattern with HPBW $120^{\circ}$

After the measuring process is finished, the antenna was applied for DVB application for DKI Jakarta and Figure 11 showed the diagram block for the inspection process of the antenna design. Yaggi antenna as seen in Figure 12 is used as comparison to analyze the perfomance of the proposed antenna design.

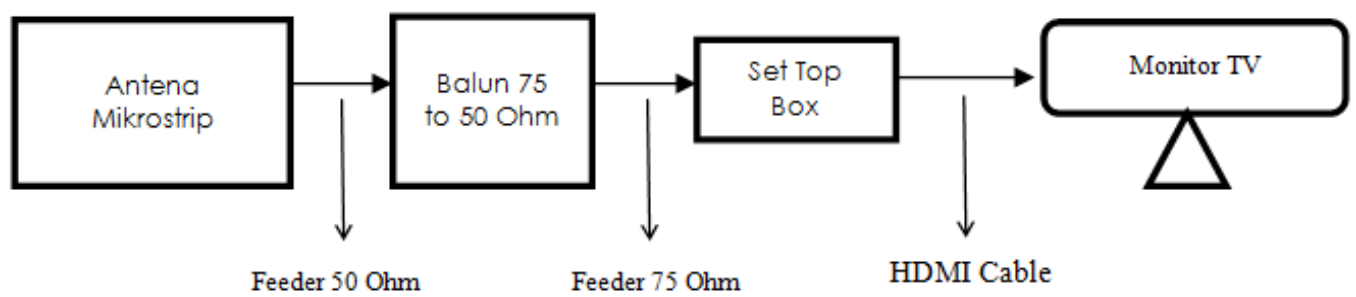

Figure 11. Diagram block of the inspection process

It can be inferred from Figure 11, that matching impedance efforts are advisable to be done between $50 \mathrm{Ohm}$ antenna impedance and the $75 \mathrm{Ohm}$ digital television receiver through its set top box adapter. It is in order to get good quality of related signal receiving sub system by minimizing its reflected signals.

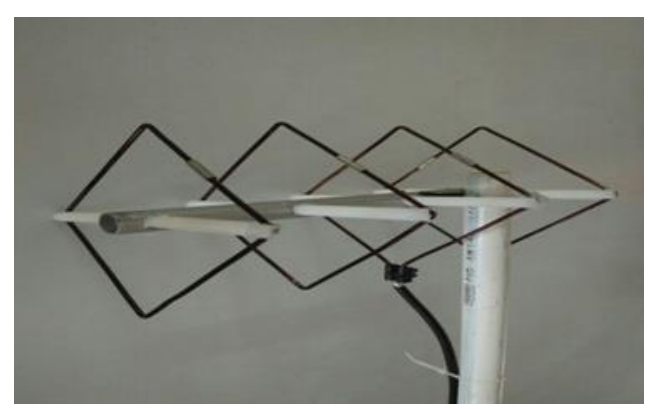

Figure 12. Antenna Yaggi model 
The results which is presented by Table 6 below showed that the proposed antenna design can receive 11 DVB application stations with high definition quality picture as seen in Figure 13, as compared to Yaggi antenna that can receive 15 stations. The proposed antenna design could not received the signal only for channel 24, such as RCTI, Global TV, and MNC TV, because gain of the antenna design is $11.62 \mathrm{~dB}$ compare with gain of the Yaggi antenna of $13 \mathrm{~dB}$.

Table 6. The Received Frequency Between Yaggi Antena and Microstrip Antenna

\begin{tabular}{clcc}
\hline No & \multicolumn{1}{c}{ TV Station } & Yaggi Antenna & Microstrip Antenna \\
\hline 1. & RCTI, Global TV, MNC TV & Received & Not Received \\
2. & Metro TV & Received & Received \\
3. & TV One, ANTV and Sport One & Received & Received \\
4. & BeritaSatu TV (BSTV) & Received & Received \\
5. & Transcorp (Trans TV, Trans 7) & Received & Received \\
& danKompas TV & Received & Received \\
6. & SCTV, Indosiar, and O-Channel & Received & Received \\
7. & RTV, Jakarta Globe & & \\
\hline
\end{tabular}
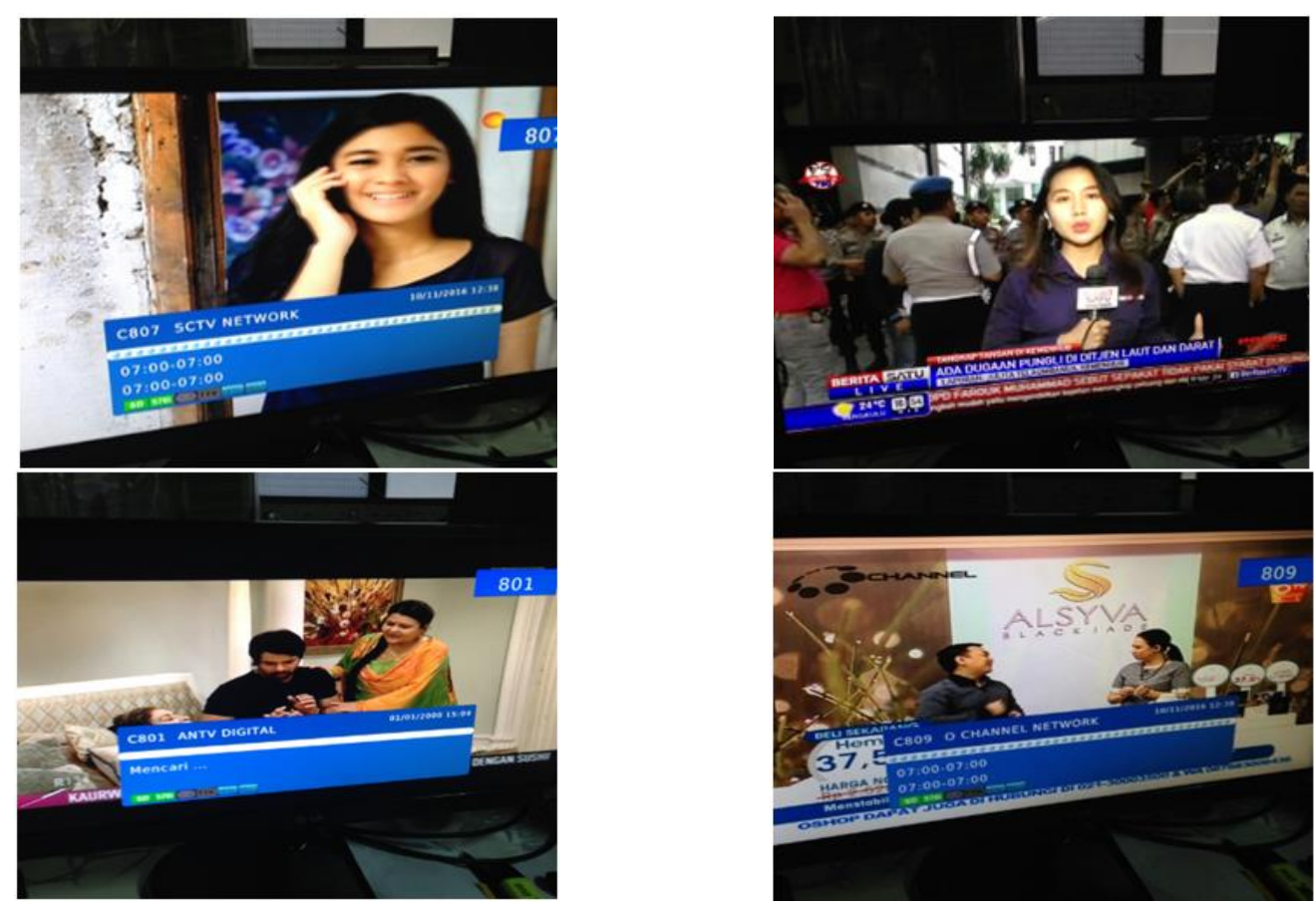

Figure 13. Quality of picture received from the proposed microstrip antenna

\section{Conclusion}

The proposed of peripheral slit microstrip antenna using log periodic technique with return loss value of $\leq-10 \mathrm{~dB}$ and VSWR value $\leq 2$ can be achieved by adjusting the dimension of the patch antenna and the slits and also the length of the feed line and the stub length. Using peripheral slits technique the dimension of the patch antenna can be reduced up to $62.6 \%$ and can produce a compact antenna with smaller dimension. Using log periodic technique can increase the bandwidth of the antenna and the impedance bandwidth from the measurement is $350 \mathrm{MHz}$ compared to $257.8 \mathrm{MHz}$ from the simulation process. The proposed antenna could receive 11 DVB stations with high definition quality picture and only channel 24 , such as $\mathrm{RCTI}$, Global TV, and MNC TV can not reveived the signal. 


\section{Acknowledgement}

The authors wish to express their gratitude to The Ministry of Research and Higher Educationn of Republik Indonesia for their support through Hibah Penelitian Unggulan Perguruan Tinggi No.777/K3K/KM/SPK.LT/2016 dated on 22th of September 2016.

\section{References}

[1] Seminar of the Ministry of Communications and Information Directorate General of Post and Informatics, Indonesia Goes Digital Communication Information, Jakarta: Administrator. 2012: 1-15.

[2] Regulation No. 05 / PER / M.KOMINFO / 02/2012 on Standards for Digital Terrestrial Television Broadcasting Revenue Fixed Not Paid (Free-To-Air). 2012: 1-3.

[3] Regulation No. 23 / PER / M.KOMINFO / 11/2011 on Master Plan (Masterplan) Radio Frequency For Purposes of Terrestrial Digital Broadcast TV On the Radio Frequency Band 478-694 MHz. 2011: 1-10.

[4] A Adrian Gulfyan Putranto, Aloysius Adya Pramudita. Designing Microstrip Slot Antenna Receiver System for Digital Television. RiTekTra, Jakarta. 2013.

[5] Sri Anggaraeni Kadiran. Log Periodic Patch Techniques to Widen Bandwidth Microstrip Antenna TV Receiver. ORBIT. 2013; 9(2).

[6] Andrew Mulia. Design and Realization Based Omnidirectional UHF Television Antenna Microstrip For Applied in Tasikmalaya Region. Telekontran. 2013; 1(2).

[7] T Isernia, A Massa, AF Morabito, P Rocca. On The Optimal Synthesis of Phase Only Reconfigurable Antenna Arrays. Proceedings of the 5th European Conference on Antennas and Propagation (EuCAP 2011). Rome, Italy. 2011: 2074-207.

[8] Hetal M Pathak et al. Design of Log Periodic Dipole Array Antenna Using Two Sides With Comparision of Two Dielectric Material Result. Journal of Information, Knowledge and Research in Electronics and Communication Engineering. 2013; 2(2).

[9] Giovani Andrea Casuladan Paolo Maxia. A Multiband Printed Log Periodic Dipole Array for Wireless Communications. International Journal of Antenna and Propagation, ume. 2014.

[10] Fang Lei et al. A Monolayer Multi Octave Bandwidth Log Periodic Microstrip Antenna. Progress In Electromagnetics Research Letters. 2013; 41: 97-104.

[11] Tauseef Tauqeer et al. Analytical Comparision of Wideband Microstrip Log Periodic and CPW Antennas. Microwave and Optical Technology Letters. 2014; 56(8).

[12] Hamed Ghanbari Forshtami et al. Wideband Log Periodic Microstrip Antenna with Elliptic Patches. Journal of Information System and Telecommunication. 2013; 1(2).

[13] Indra Surjati et al. Antenna Peripheral Slits Berbentuk Cincin Persegi Dengan Pencatuan Electromagnetic Coupled. Seminar Nasional Microwave. Antenna dan Propagasi (SMAP) 2013, Department of Electrical Engineering FT Universitas Indonesia. 2013. 